\title{
Discrimination of individual vocalizations by black-capped chickadees (Poecile atricapilla)
}

\author{
LESLIE S. PHILLMORE, CHRISTOPHER B. STURDY, MARTHA-RAE M. TURYK, \\ and RONALD G. WEISMAN \\ Queen's University, Kingston, Ontario, Canada
}

\begin{abstract}
The auditory perceptual abilities of male black-capped chickadees (Poecile atricapilla) were examined using an operant go/no-go discrimination among 16 individual vocalizations recorded at $5 \mathrm{~m}$. The birds learned to discriminate about equally well among eight male chickadee fee-bee songs and eight female zebra finch (Taeniopygia guttata) distance calls. These results do not indicate that chickadees have a species-specific advantage in individual recognition for conspecific over heterospecific vocalizations. We then transferred the chickadees to a discrimination of the same songs and calls rerecorded at a moderate distance. These results showed accurate transfer of discrimination from 16 vocalizations recorded at $5 \mathrm{~m}$ to novel versions of the same 16 songs and calls rerecorded at $25 \mathrm{~m}$. That is, chickadees recognized individual songs and calls despite degradation produced by rerecording at $25 \mathrm{~m}$. Identifying individual vocalizations despite their transformation by distance cues is here described as a biologically important example of perceptual constancy.
\end{abstract}

Songbirds use their vocalizations to communicate with conspecifics over distances of several meters to several hundreds of meters. Both male and female songbirds produce vocalizations that contain unique information that assists conspecifics to recognize the singer as a mate, offspring, or a territorial neighbor(see Wiley, 2000). Also, songbirds use the degradation of vocalizations in the environment to determine the location of the singer in azimuth, elevation, and distance (B. S. Nelson \& Stoddard, 1998).

The study species for the present research was blackcapped chickadees (Poecile atricapilla), who, in common with other songbirds, must perform complex auditory recognition tasks to defend a territory and recognize their mates. Specifically, male chickadees must be able to discriminate among the vocalizations of territorial neighbors and between the vocalizations of these familiar neighbors and unfamiliar strangers. Furthermore, a male must be able to determine the location of the vocalizations of both neighbors and strangers at almost any distance within or outside of its territory. A conspecific neighbor heard from the direction of an incorrect boundary or within the territory or an unknown conspecific heard within the territory constitutes a potential threat, which can require aggressive behavior to protect a mate or resources (McGregor, 1991).

Investigationinto the recognition of specific vocalizations has progressed both in field studies of territorial behavior and in operant discrimination studies of songbirds' percep-

This research was supported by a grant from the Natural Science and Engineering Research Council of Canada. We thank Alexandra Hernandez for helping to run the pilot study for this research, Scott Ramsay for helping with the recordings, Richard Zann for donation of zebra finch recordings, and Laurene Ratcliffe for reading an earlier version of this article. Correspondence about this article should be addressed to R. G. Weisman, Department of Psychology, Queen's University, Kingston, ON, K7L 3N6 Canada (e-mail: ron@psyc.queensu.ca). tual abilities. Field studies of individual song and call recognition use variants of the neighbor-stranger playback paradigm. For example, it is well known that territorial male songbirds react more aggressively to vocalizations of a conspecific stranger than to the vocalizations of a neighbor (e.g., white-throated sparrows, Zonotrichia albicollis, Brooks \& Falls, 1975; song and swamp sparrows, Melospiza melodia and Melospiza georgiana, Searcy, McArthur, Peters, \& Marler, 1981; American redstarts, Setophaga ruticilla, and yellow warblers, Dendroica petechia, Weary, Lemon, \& Perreault, 1992). Notice that these studies show that songbirds respond more to familiar than to unfamiliar vocalizations, which is not necessarily the same as recognizing territorial neighbors among strangers (but see Shy \& Morton, 1986).

A two-part field study permits stronger conclusions. (1) When neighbors' and strangers' songs are played back from the neighbor's correct boundary, strangers' songs elicit stronger territorial responses. (2) When played back from an incorrect boundary, both neighbors' and strangers' songs elicit equally strong territorial responses (e.g., whitethroated sparrows, Falls \& Brooks, 1975; hooded warblers, Wilsonia citrina, and Kentucky warblers, Oporornis formosus, Godard \& Wiley, 1995). This work shows that songbirds can take into account location when deciding whether to give territorial responses to a song. The ideal demonstration that songbirds recognize their territorial neighbors by song would require recognition of all of a bird's neighbors and reasonable stability in the pattern of recognition responses. Repeated territorial responses to the playback of several birds' songs are precisely what one cannot obtain in field research. Birds habituate to individual vocalizations and, indeed, to the whole protocol rapidly during field playback studies, which, therefore, must be confined to just a few trials per subject. 
In laboratory operant studies, attention to song is maintained (i.e., habituation is not an issue) because the birds must discriminate among vocalizations to gain access to food rewards. In this stable protocol, researchers can study aspects of the recognition of individual vocalizations untestable in natural settings - for example, memory capacity, ability to discriminate heterospecific vocalizations, and transfer of training across song types. For example, operant go/no-go discrimination studies have demonstrated that barn and cliff swallows (Hirundo rustica and Hirundo pyrrhonota) can discriminate at least 10 pairs of individual vocalizations (Loesche, Stoddard, Higgins, \& Beecher, 1991) and that song sparrows can discriminate among as many as 32 pairs of conspecific vocalizations (Stoddard, Beecher, Loesche, \& Campbell, 1992). We need to distinguish between studies of the discrimination of individual vocalizations, as in the present study (also Loesche et al., 1991; Stoddard et al., 1992), and (much rarer) tests of the recognition of the voice characteristics of individual birds, as in transfer across different vocalizations from the same bird (see Gentner \& Hulse, 1998; Weary \& Krebs, 1992).

Not only can songbirds recognize neighbors and their locations, they also can judge the distance to their neighbors (i.e., range conspecific vocalizations) on the basis of distortion and degradation in the signal caused by transmission over distance (e.g., Naguib, 1995, 1997). These changes in acoustic structure (e.g., decreased overall amplitude, attenuation of high-frequency components, increased reverberation within and at the end of the signal from the ground and vegetation, and decreased signal-to-noise ratio; see Dabelsteen, Larsen, \& Pedersen, 1993) are known to aid songbirds in estimating the distance to a vocalizing conspecific (e.g., Naguib, 1995, 1997).

It is a curious paradox that the cues that make judgment of distance possible may eventually have the effect of rendering recognition of a specific conspecific difficult, if not impossible. At some point, it is possible that degradation of the signal from transmission over distance may occlude the identity of the singer contained within that signal.

In a previous article, we reported on how chickadees use distance cues to discriminate among vocalizations recorded at difference distances from a microphone and then played back at the same distance from the bird as discriminative stimuli in an operant discrimination (Phillmore, Sturdy, Ramsay, \& Weisman, 1998). In the present article, we report on how chickadees discriminate among individual conspecific and heterospecific vocalizations and whether there is a species-specific advantage for discriminating among conspecific vocalizations. We also examine how introducing distance cues affects the recognition of individual vocalizations.

\section{GENERAL METHOD}

\section{Subjects}

Seven experimentally naive adult male black-capped chickadees captured as adults ( $\geq 1$ year) from the wild within $50 \mathrm{~km}$ of Kingston,
Ontario, Canada (under Environment Canada permit CA001) participated in the experiment. The birds were housed in a room with other conspecifics, but in individual cages in the laboratory, for at least 2-3 months prior to the experiment. The chickadees did not have exposure to zebra finch vocalizations prior to this experiment. One chickadee became ill between discrimination training and reversal testing and was retired from the experiment.

The chickadees were fed a mixture of three parts crushed unsalted sunflower seeds, two parts isolated soy protein (Tara Natural Foods, Kingston, ON, Canada), one part Purinature turkey starter (Purina, Woodstock, ON, Canada), and vitamin supplement (Theralin, Cranbury, NJ). Water, grit and cuttlebone were freely available. On alternate days, we added a vitamin supplement (Hagen Vitamin Supplement Conditioner for Birds, Montreal, PQ, Canada) to the water. Once a week, as a further nutritional supplement, we fed the birds a small amount of hard-boiled egg and alfalfa sprouts.

Prior to the experiment, the birds lived on a light:dark cycle typical for the season in Kingston, Ontario. For the duration of the experiments (about 3 months), the birds lived on a 15:9-h light:dark cycle to simulate light conditions during the spring, when chickadees establish territories and begin breeding. We speculate that the birds were photostimulated at the beginning of the experiment (owing to the change to long days) but that they may have become photorefractory over the course of the experiment (from extended exposure to long days; see Dawson, King, Bentley, \& Ball, 2001, for a recent review of photoperiodicity in birds). Temperature was maintained at a constant $20^{\circ} \mathrm{C}$.

\section{Apparatus}

Each bird worked in a standard budgerigar cage $(0.3 \mathrm{~m}$ wide $\times$ $0.4 \mathrm{~m}$ high $\times 0.4 \mathrm{~m}$ deep). A wire floor, attached near the bottom of the cage, ensured that spilled food was not eaten. Each cage was contained in a ventilated, sound-attenuating enclosure and was lighted by a $9-\mathrm{W}$ twin-tube fluorescent bulb. Each cage contained several perches, a water bottle, and a grit container. An opening $(0.11 \mathrm{~m}$ wide $\times 0.16 \mathrm{~m}$ high) in the cage allowed the bird access to the feeder (Njegovan, Hilhorst, Ferguson, \& Weisman, 1994). A perch in front of the feeder opening and the feeder itself were equipped with infrared sensors to monitor the position of the bird. A microcomputer controlled the experiment and recorded the responses in each chamber. Stimuli were stored in Macintosh Plus computers (Apple Computer, Cupertino, CA) and were played at 22-k 8-bit samples per second, using a NAD 310 integrated amplifier (overall, $\pm 0.3 \mathrm{~dB}, 20-$ $20000 \mathrm{~Hz}$; NAD Electronics Ltd., London, England) through a Realistic Minimus-7 speaker (Radio Shack, Barrie, ON) beside the feeder.

\section{Stimulus Preparation}

Our goal was to produce recordings of the same vocalizations at two distances from the source to serve as discriminative stimuli. When recording free-living birds, it is often difficult to minimize and standardize the distance between the bird and the microphone. This produces variability in the amount of degradation present in source vocalizations, which is compounded by rerecording meant to degrade the signal over standard distances. Because distance effects were an important factor in our experiment, we used simulated (rather than only digitized) vocalizations, because we could eliminate any distance effects present in recordings of natural (original) song. Specifically, background noise and reverberation visible either in sound spectrograms or in fast Fourier transforms (FFTs) were eliminated. It is possible that the synthesizing process also reduced the cues in the vocalizations used for recognition; however, it was essential to balance between preserving individual cues and eliminating distance effects in the source stimuli.

The prototypes for our simulations were the songs of eight freeliving male black-capped chickadees recorded in the wild at the 
Queen's University Biology Station (see Weisman, Ratcliffe, Johnsrude, \& Hurley, 1990) and the distance calls of eight free-living female zebra finches recorded in the wild at Alice Springs and northern Victoria, Australia. The birds in the experiment had no previous experience with any of the vocalizations used here. We digitized these vocalizations into a Power Macintosh 7100 (Apple Computer, Cupertino, CA), using Sound Designer II software and an Audiomedia Digital Signal Processing Board (Digidesign, Menlo Park, CA), at 44-k 16-bit samples per second.

We used the digitally sampled vocalizations to obtain numerical values for frequency $(\mathrm{Hz})$ and amplitude (dB SPL) over time, using SoundScope 8 (GW Instruments, Somerville, MA), and then input the numerical values into TurboSynth SC software (Digidesign, Menlo Park, CA) to create synthetic copies. Frequency and amplitude measures were taken every $12.5 \mathrm{msec}$ in sampled zebra finch calls (average duration $=311.5 \mathrm{msec}, S D=45.3 \mathrm{msec}$ ) and every $25 \mathrm{msec}$ in sampled chickadee songs (average duration $=1,256.1 \mathrm{msec}, S D=$ $109.8 \mathrm{msec}$ ). Differences in sampling rate reflect differences in the acoustic structures being measured; zebra finch distance calls have more rapid frequency and amplitude modulation than do chickadee songs. Therefore, the number of times each vocalization was sampled for frequency and amplitude information varied depending on the length of the stimulus. We included peak numerical values from the FFTs in the simulations and excluded values for background noise and reverberation within and at the end of each vocalization. In doing so, we eliminated distance cues (e.g., signal-to-noise ratio and reverberation) present in the digitized samples from our simulations. Sample frequency and amplitude measures were input into TurboSynth SC software (Digidesign, Menlo Park, CA) to create synthetic copies of the prototypes.

Although we cannot claim that our simulations were exact replicas of the original stimuli-for example, by including phase information-we used sonograms, FFTs, and the human ear to compare the simulations with their prototypes to ensure that synthesis was as accurate as our capabilities allowed. We verified the validity of our simulations in informal playback experiments (see Phillmore et al., 1998). We played our simulated male chickadee songs to free-living male chickadees, and we played female zebra finches distance calls to male zebra finches. Each type of synthesized stimulus produced species-typical responses in male conspecif ics similar to those elicited by natural vocalizations and had been used as the source for producing the signals in previous experiments (see Phillmore et al., 1998).

We made recordings of the simulated vocalizations in an area known to be inhabited by black-capped chickadees (Pangman Conservation Reserve, Queen's University Biology Station, about 50 km north of Kingston, ON, Canada). The terrain is relatively flat and well forested (coniferous and deciduous trees); we recorded in fall, but the amount of foliage was comparable to that in early spring, when chickadees are breeding. We recorded between 0700 and 1000 EST over 3 days. Weather conditions were similar on all recording days.

A Sony TCD-D7 DAT player (overall, $\pm 1 \mathrm{~dB} ; 20-20000 \mathrm{~Hz}$ ) and a Sony SRS-77G amplified speaker were used to play simulated calls, and a Sony Walkman Professional WM-D6C (overall, $\pm 3 \mathrm{~dB}$; $40-15000 \mathrm{~Hz}$ ) and a Sennheiser MKH-816 shotgun microphone (overall, $\pm 1.5 \mathrm{~dB} ; 200-10000 \mathrm{~Hz}$ ) were used to record them. The playback speaker was mounted on a pole with the center of the woofer $1.5 \mathrm{~m}$ from the ground, a height at which both chickadees and zebra finches are known to sing. The microphone was mounted on a tripod so the center of the end of the baffle was $1.5 \mathrm{~m}$ from the ground and aimed directly at the speaker. The amplitude of the stimuli was set at $80 \mathrm{~dB}$ SPL when measured $1 \mathrm{~m}$ away from the speaker and $1.5 \mathrm{~m}$ from the ground, using a Realistic Sound Level Meter (Radio Shack, Barrie, ON, Canada). The amplitude of the stimuli and the recording level on the Walkman Pro were not adjusted during recording.

In a pilot experiment, we failed to obtain transfer from vocalizations recorded at $5 \mathrm{~m}$ to rerecordings of the same vocalizations made at 50 and $75 \mathrm{~m}$. We are uncertain whether this failure was due to the methodology of the pilot study (which used only occasional probe trials) or to the amount of degradation in our particular rerecordings at 50 and $75 \mathrm{~m}$. In prior research (Phillmore et al., 1998), chickadees showed transfer (i.e., different levels of responding) between 5- and $25-\mathrm{m}$ vocalizations. Given that we failed to obtain transfer with 50 and 75-m stimuli in our pilot experiment, we decided to test for transfer over distance cues with 25 -m vocalizations.

Simulated vocalization s were recorded 5 and $25 \mathrm{~m}$ from the speaker, yielding two sets of stimuli: the 5- and 25 -m vocalization sets. Each set of vocalizations consisted of eight simulated chickadee songs

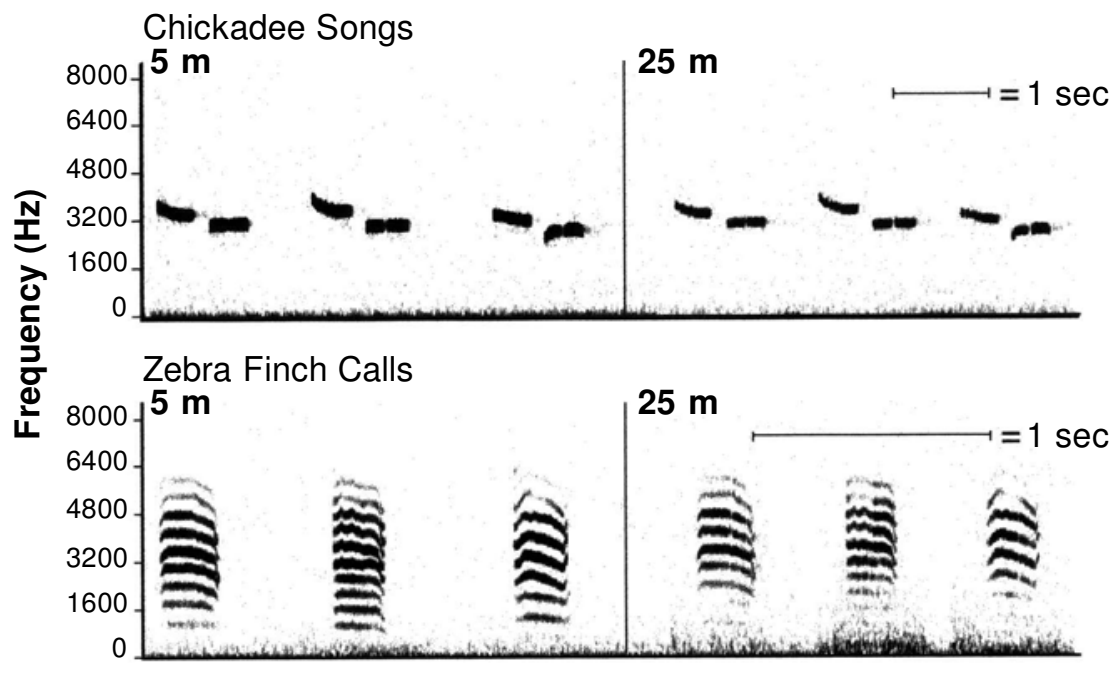

Figure 1. Sound spectrograms (FFT settings: hamming window, 1,024 FFT points, 184-Hz filter) of male black-capped chickadee songs (top) and female zebra finch distance calls (bottom). The vocalizations of three individuals of each species are shown at $5 \mathrm{~m}$ (training stimuli) and $25 \mathrm{~m}$ (transfer stimuli). 
and eight simulated zebra finch calls. Figure 1 shows sound spectrograms of three chickadee songs and three zebra finch distance calls recorded at each distance. In comparing the two sets of vocalizations, those recorded at $25 \mathrm{~m}$ are decreased in amplitude (and therefore in signal-to-noise ratio as well) and, theoretically, have increased reverberation and high-frequency attenuation, as compared with the vocalizations recorded at $5 \mathrm{~m}$ (in the experiment, playback of the 5-m vocalizations in the operant chamber was standardized to approximately $75 \mathrm{~dB}$ ). For both sets of vocalizations, we compared the loudest points in the average peak spectrograms (512-point window, $150-\mathrm{Hz}$ filter; SoundScope 8 ) in the 5-m vocalizations with the 25 - $\mathrm{m}$ vocalizations. On average, chickadee songs decreased in amplitude by $11.83 \mathrm{~dB}(S D=3.14)$. Closer examination of the average peak spectrograms of chickadee songs showed that the fee note (average $=3509.91 \mathrm{~Hz}, S D=143.76)$ dropped in amplitude by an average of $13.39 \mathrm{~dB}(S D=2.00)$ and the bee note (average $=3068.41 \mathrm{~Hz}$, $S D=137.64)$ dropped in amplitude by an average of $11.11 \mathrm{~dB}(S D=$ 3.14). Thus, the higher frequency fee was attenuated more than the lower frequency bee. Zebra finch calls, on average, decreased in amplitude by $10.61 \mathrm{~dB}(S D=2.44)$. Zebra finch calls were much more complex to analyze than chickadee songs, since higher frequency attenuation was confounded by the relative amplitude of harmonics within the note; that is, higher frequencies were sometimes louder than lower frequencies to begin with, thus masking any effects of relative frequency attenuation. Also, zebra finch calls are much more frequency modulated over a shorter amount of time than are chickadee notes, potentially obscuring any frequency attenuation. When analyzed by frequency range, the average decrease in mean peak amplitude for zebra finch calls was $8.7 \mathrm{~dB}(S D=2.16)$ for $2-3 \mathrm{kHz}$, $9.4 \mathrm{~dB}(S D=2.91)$ for $3-4 \mathrm{kHz}, 8.36 \mathrm{~dB}(S D=1.98)$ for $4-5 \mathrm{kHz}$, and $7.79 \mathrm{~dB}(S D=2.89)$ for $5-6 \mathrm{kHz}$. Therefore, for both chickadee songs and zebra finch distance calls, distance had a greater, quantifiable degradation effect on vocalizations recorded at $25 \mathrm{~m}$, as compared with the same vocalizations recorded at $5 \mathrm{~m}$.

We digitized the 5- and 25-m vocalization sets at 44-k 16-bit samples per second and all at the same input level with Sound Designer II software. The files were converted to 22-k 8-bit samples per second using WaveConvert software (Waves, Tel-Aviv, Israel) and the L1 Ultramaximizer Plug-In (Waves, Tel-Aviv, Israel) for Sound Designer II, respectively. To eliminate aliasing prior to conversion, the files were digitally low-pass filtered $(<10007 \mathrm{~Hz})$ with Q10 Paragraphic Equalizer Plug-In (Waves, Tel-Aviv, Israel) for Sound Designer.

\section{Procedure}

Nondifferential training. Nondifferential training began after a bird learned to use the perch and feeder. The within-trial sequence began when the bird landed on the perch, breaking an infrared beam. If the bird remained on the perch for $1 \mathrm{sec}$, a stimulus was selected randomly and without replacement from the stimulus pool and played once in its entirety. If the bird entered the feeder (breaking another infrared beam) after the stimulus played, the bird was rewarded with $1 \mathrm{sec}$ of access to food. A 30 -sec intertrial interval (ITI) followed. If the bird left the perch without entering the feeder, the trial ended after $1 \mathrm{sec}$. If the bird remained on the perch for more than $1 \mathrm{sec}$, the trial ended following stimulus offset, and then a 60-sec ITI occurred. This procedure encouraged the birds to leave the perch on all trials. If the bird left the perch before the stimulus had finished playing, the trial ended, and the chamber lights turned off for a 5-sec ITI to ensure that the birds remained on the perch to hear the entire stimulus. During nondifferential training, the birds heard both the 5- and the $25-\mathrm{m}$ vocalization sets (i.e., all the songs and calls used in the experiment). We used nondifferential training to create a high and uniform rate of response across all the stimuli. This ensured that differential responding to unrewarded stimuli during discrimination training was learned.
Discrim ination training. Discrimination began after a minimum of 4 days of nondifferential training. Here, visits to the feeder after rewarded $(\mathrm{S}+)$ stimuli still resulted in 1-sec access to food, but visits to the feeder after unrewarded $(\mathrm{S}-$ ) stimuli resulted in a 30sec ITI with the chamber lights out. As in nondifferential training, individual stimuli were selected randomly and without replacement from the vocalization set and were played. Training during the light portion of the day produced about 1,000 trials per session (day).

\section{Response Measures}

As a measure of discrimination and performance during training, we calculated discrimination ratios for performance on each of the chickadee song stimuli and the zebra finch call stimuli. For example, to calculate the ratio for chickadee songs, we divided the average percentage response to the $S+$ songs by the average percentage response to $\mathrm{S}+$ and $\mathrm{S}-$ songs. Discrimination is at chance level when the ratio is .50 (responding to all vocalizations equally) and perfect when the ratio is 1 (responding to only $\mathrm{S}+$ stimuli).

Although discrimination ratios give a measure of how well a bird has discriminated, it can be misleading: A bird could discriminate perfectly $($ ratio $=1$ ) by responding to only one $S+$ and ignoring all the other stimuli. The confidence interval $(\mathrm{CI})$ provides a measure of how many of the individual $\mathrm{S}+$ are discriminated. We adopted a measure from prior studies (e.g., Njegovan \& Weisman, 1997; Weisman, Njegovan, \& Ito, 1994): the two-tailed 95\% CI from standard statistical methods (Sokal \& Rohlf, 1980). In this adaptation, the 95\% CI was calculated from the mean and standard deviation $(S D)$ of the percentage of responses to the $S$ - stimuli, but separately for songs and calls in each session. In the absence of a true difference in responding to an individual $\mathrm{S}+$ vocalization and to the relevant $\mathrm{S}-$ vocalizations, we would expect that the response to that $\mathrm{S}+$ would be included in the confidence interval in 19 out of 20 replications (Sokal \& Rohlf, 1980). In other words, when an individual $\mathrm{S}+$ exceeds the $95 \% \mathrm{CI}$ for $\mathrm{S}-$ songs or calls, we provide solid statistical evidence that it is well discriminated. We analyzed the percentage of $\mathrm{S}+$ stimuli $>95 \% \mathrm{CI}$ at the end of the first $(4 \mathrm{~S}+)$ and second $(8 \mathrm{~S}+)$ phases of discrimination training.

\section{Statistical Analyses}

When the discrimination ratio is near .50 or 1 , sample values may not be normally distributed. Hence, we conducted parallel analyses of variance (ANOVAs) of the ratios and of arcsine square-root transformations of the ratios. The percentage of standards $>95 \%$ CI may lack a normal sampling distribution. As a check on the effects of possible violations of normality, we conducted analyses using only ranks of the percentage of standards $>95 \% \mathrm{CI}$. An ANOVA of ranks is a kind of nonparametric analysis (see Conover \& Iman, 1981). In each instance, an analysis of transformed data yielded virtually the same levels of significance as an analysis of the untransformed data; we report the results for ANOVAs of the untransformed data here.

\section{EXPERIMENT 1}

\section{Discrimination Among Individual Vocalizations}

Here, we examined chickadees' discriminations among individual vocalizations of conspecifics and heterospecifics, using a laboratory task based on food rewarddiscriminations not possible to study in a field setting, since birds rarely attend to heterospecific vocalizations in territorial situations (Slater \& Catchpole, 1990). We asked the birds to discriminate among chickadee songs and zebra finch distance calls recorded from a distance of $5 \mathrm{~m}$. We included both conspecific and heterospecific vocalizations in order to test the generality of the use of distance cues, 
but we had reason to expect a species-specific advantage in operant discriminations among vocalizations by songbirds (Dooling, Brown, Klump, \& Okanoya, 1992). We sought to determine whether chickadees could discriminate among these songs and calls and whether they might have an advantage in discriminating among conspecific vocalizations, relative to discriminating among heterospecific vocalizations.

\section{Method}

Discrimination consisted of two phases. During the first phase, we presented eight different individuals' vocalizations from the 5-m vocalization set: four songs and four calls. Two of the songs and two of the calls were $\mathrm{S}+$, and the other two songs and two calls were $\mathrm{S}-$. During the second phase, we added the remaining eight individuals' vocalizations from the 5-m set, again assigning half the songs and calls to serve as $\mathrm{S}+$ and $\mathrm{S}-$, respectively. We counterbalanced across subjects which eight individuals' vocalizations were presented during the first phase and which were added during the second phase. Training continued for at least 6,000 trials.

\section{Results}

Figure 2 shows acquisition of discrimination and final day discrimination for $4 \mathrm{~S}+\mathrm{s}$ (two chickadee songs and two zebra finch calls) and for $8 \mathrm{~S}+\mathrm{s}$ (four songs and four calls). During the $4 \mathrm{~S}+$ discrimination, accuracy increased over blocks of training trials to the final training day. Transfer to the $8 \mathrm{~S}+$ discrimination resulted in a reduction in the discrimination ratio, but not to levels seen in the first block of the acquisition of the $4 \mathrm{~S}+$ discrimination. In other words, the birds were still well above chance on the stimuli from the $4 \mathrm{~S}+$ discrimination but performed more poorly with the 4 added $S+$ stimuli. After further training on the $8 \mathrm{~S}+$ discrimination, chickadees accurately discriminated the $\mathrm{S}+$ vocalizations from the
$\mathrm{S}-$ vocalizations. In fact, by the final day of training, the birds discriminated $8 \mathrm{~S}+$ stimuli (DRs $\geq .93$ ) slightly better than they had previously discriminated four $\mathrm{S}+\mathrm{s}$ (DRs $\geq$ .89). Also, Figure 2 shows that acquisition proceeded virtually identically for the discrimination of both types of vocalizations (i.e., songs and calls).

To evaluate acquisition, we conducted repeated measures (vocalization type $\times$ trial block) ANOVAs separately for the $4 \mathrm{~S}+$ and the $8 \mathrm{~S}+$ discriminations. In both analyses, we found significant effects for blocks of training trials $\left[F_{\mathrm{s}}(3,18) \geq 7.34, p \mathrm{~s} \leq .002\right]$, no significant effects for vocalization type $\left(F_{\mathrm{S}}<1\right)$, and no significant vocalization type $\times$ block interactions $\left[F_{\mathrm{s}}(3,18) \leq 2.39, p_{\mathrm{s}} \geq .1\right]$.

To evaluate transfer from the $4 \mathrm{~S}+$ to the $8 \mathrm{~S}+$ discrimination, we conducted a repeated measures (vocalization type $\times$ discrimination task) ANOVA. We found a significant drop in the discrimination ratio from the final day of the $4 \mathrm{~S}+$ discrimination to the first block of the $8 \mathrm{~S}+$ discrimination $[F(1,6) \geq 24.77, p=.003]$. To compare final day performance on the two discriminations, we conducted a repeated measures (vocalization type $\times$ discrimination task) ANOVA. We found no significant difference in final day performance on the $4 \mathrm{~S}+$ and $8 \mathrm{~S}+$ discriminations $(F<1)$ and no significant difference in final day performance between the two vocalization types $(F<1)$.

As we noted earlier, songbirds sometimes achieve high discrimination ratios in go/no-go discriminations by responding extensively to only some of the $\mathrm{S}+$ exemplars, while responding little to other $\mathrm{S}+\mathrm{s}$ and all the $\mathrm{S}-\mathrm{s}$. Chickadees discriminated $4 \mathrm{~S}+\mathrm{s}$ (two songs and two calls) and $8 \mathrm{~S}+\mathrm{s}$ (four songs and four calls) with almost no errors. The mean percentage of $\mathrm{S}+\mathrm{s}>95 \% \mathrm{CI}$ at the end of discrimination training for the $4 \mathrm{~S}+\mathrm{s}$ was $100 \%$

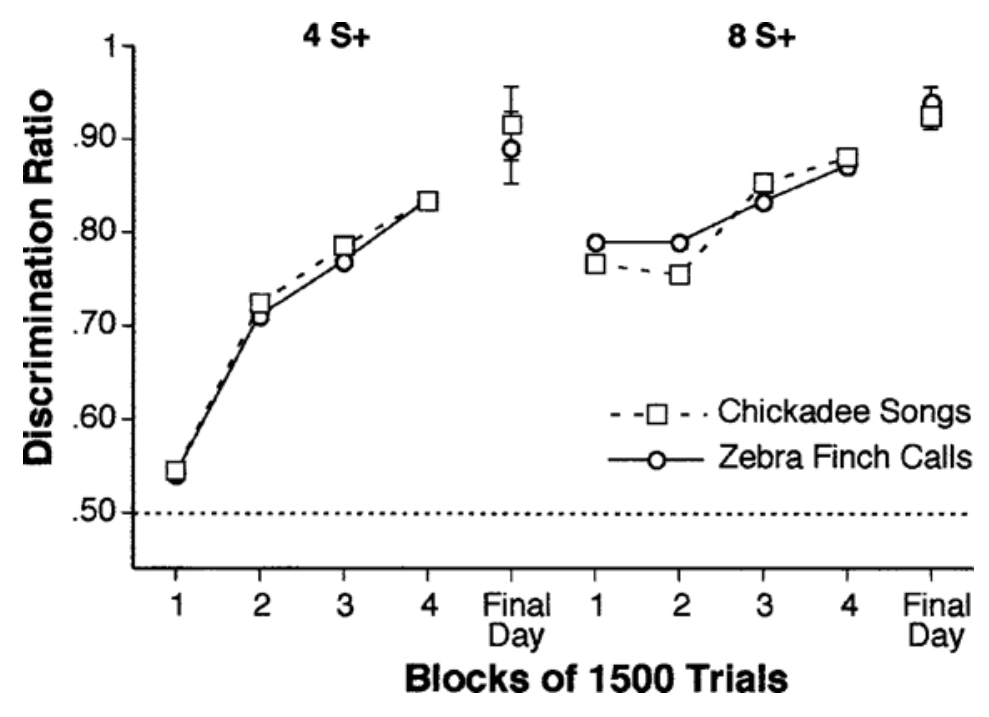

Figure 2. Discrimination ratios during acquisition and on the final day of the $4 \mathrm{~S}+$ and $8 \mathrm{~S}+$ tasks. Ratios for the discrimination of zebra finch calls are represented by circles, and ratios for chickadee songs are represented by squares. 
$(S D s=0)$ for both chickadee songs and zebra finch calls. The mean percentage of $\mathrm{S}+\mathrm{s}>95 \% \mathrm{CI}$ at the end of discrimination training for the $8 \mathrm{~S}+\mathrm{s}$ was $85.71 \%(S D=$ $19.67)$ for chickadee songs and $96.43 \%(S D=9.45)$ for zebra finch calls. We conducted a repeated measures (percentage of $\mathrm{S}+\mathrm{s} \times$ vocalization type) ANOVA on the $95 \%$ $\mathrm{CI}$ data and found no significant difference in the percentage of $\mathrm{S}+\mathrm{s}>95 \% \mathrm{CI}$ between the final day of the $4 \mathrm{~S}+$ discrimination and the final day of the $8 \mathrm{~S}+$ discrimination $[F(1,6)=3.947, p=.094]$. Also, we found no significant difference between vocalization types (songs and calls) in either the 4 or the $8 \mathrm{~S}+$ discrimination tasks $[F(1,6)=2.077, p=.199]$. In summary, the birds discriminated virtually all the individuals' songs and calls with high accuracy.

\section{EXPERIMENT 2 Transfer to Degraded Vocalizations}

We sought to determine whether chickadees can transfer their discrimination among individual vocalizations (learned in Experiment 1) to versions of the same vocalizations degraded over distance. That is, after birds learned to discriminate among vocalizations recorded at $5 \mathrm{~m}$, we tested them with the same vocalizationsrerecorded at $25 \mathrm{~m}$.

We adapted our reversal method from the discrimination reversal procedure used by Astley and Wasserman (1992) to test for the transfer of category learning in pigeons. In the discrimination reversal procedure, novel test stimuli (from the same categories as the training stimuli) are substituted for the training stimuli. However, responses to categories rewarded during original training are not rewarded during the test, and responses to categories not rewarded during original training are rewarded during the test. Negative transfer is demonstrated when birds continue to respond to the test stimuli as if the contingencies from original training were still in effect. In our adaptation of the reversal procedure, we substituted test stimuli (rerecorded at $25 \mathrm{~m}$ ) for training stimuli (recorded at $5 \mathrm{~m}$ ). We hypothesized that the chickadees would continue to discriminate the vocalizations as in original training, despite the test vocalizations' being degraded by distance.

Our rationale for conducting tests of both positive and negative transfer and including only novel stimuli in the transfer test was as follows. In previous studies, we had obtained very persistent negative transfer (Sturdy, Phillmore, \& Weisman, 2000), using a reversal design similar to that used here, giving evidence not only for the occurrence of transfer, but also for the strength. Also, in prior research presenting novel stimuli as probe trials, we had obtained less predictable transfer. Therefore, using the discrimination reversal procedure here allowed us to provide a more reliable test for both the occurrence and the persistence of transfer.

\section{Method}

At the end of discrimination training in Experiment 1, 2 of the birds were not responding to all of the $\mathrm{S}+$ vocalizations. This raises problems for testing transfer of discrimination from these vocalizations, so we gave these birds additional 4-h "tutorial" sessions to force them to respond to the $\mathrm{S}+$ vocalizations they had systematically excluded. During these additional tutorial sessions, we presented only an excluded $\mathrm{S}+$ vocalization and one randomly selected $\mathrm{S}-$ vocalization. We continued these sessions until the birds responded to all the excluded $\mathrm{S}+$ vocalizations. Finally, we returned the birds to the full discrimination task for a few sessions $(M=2.33$, $S D=1.5$ ) to measure discrimination performance. These birds were divided evenly between the two transfer groups described below.

For all the birds, we substituted the $25-\mathrm{m}$ vocalization set for the 5 -m set used in original discrimination training. For half the birds (the consistent group, $n=3$ ), the same individuals' vocalizations were kept as $\mathrm{S}+\mathrm{s}$ and $\mathrm{S}-\mathrm{s}$ as those used during original training. For the remaining birds (the reversal group, $n=3$ ), the $S+s$ of original training became $\mathrm{S}-\mathrm{s}$, and the $\mathrm{S}-\mathrm{s}$ became $\mathrm{S}+\mathrm{s}$. Therefore, we tested both positive (with the consistent group) and negative (with the reversal group) transfer to the $25-\mathrm{m}$ vocalization set. Transfer training continued for about 2,000 trials.

\section{Results}

Long-term transfer effects. Figure 3 shows performance during the final day in the $8 \mathrm{~S}+$ discrimination and during transfer to discrimination training with the $25-\mathrm{m}$ stimulus set. Chickadees in the consistent group showed a small drop in performance between the 5- and the $25-\mathrm{m}$ discriminations but maintained the discrimination among individual vocalizations. Chickadees in the reversal group showed a large and persistent drop in performance between the 5- and the 25-m discriminations. Performance remained at below-chance levels for several hundred trials, but after the first 1,000 trials, the birds in the reversal groups appeared to begin to learn that the $\mathrm{S}+\mathrm{s}$ and the $\mathrm{S}-\mathrm{s}$ were reversed.

To evaluate transfer from the 5-m to the $25-\mathrm{m}$ discrimination, we conducted a mixed (transfer group $\times$ vocalization type $\times$ distance) ANOVA and found significant main effects of transfer group $[F(1,4)=190.35, p=.0002]$ and distance $[F(1,4)=133.52, p=.0003]$ and a significant transfer group $\times$ distance interaction $[F(1,4)=22.07, p=.009]$. Analysis of simple effects showed that for both the consistent and the reversal groups, discrimination ratios dropped from the 5-m to the $25-\mathrm{m}$ discrimination.

To evaluate performance on the 25 -m discrimination, we conducted a mixed (transfer group $\times$ vocalization type $X$ trial block) ANOVA and found significant effects for differences between the consistent and the reversal groups $[F(1,4)=83.68, p=.0008]$ and across trial blocks $[F(1,4)=$ $10.12, p=.0013]$ and a significant transfer group $\times$ vocalization type interaction $[F(1,4)=13.23, p=.022]$. This significant interaction suggests that the chickadees in both the positive (consistent) and the negative (reversal) transfer groups showed stronger transfer to zebra finch (heterospecific) calls than to chickadee (conspecific) songs. However, analysis of simple effects showed only a trend toward this result $\left[F_{\mathrm{s}}(1,4) \geq 6.09, p_{\mathrm{s}} \leq .069\right]$. In summary, the chickadees showed prolonged positive and negative transfer over the first 1,000 trials between the prior discrimination of 5-m vocalizations and the later discrimination of $25-\mathrm{m}$ versions of the same individuals' songs and calls. 


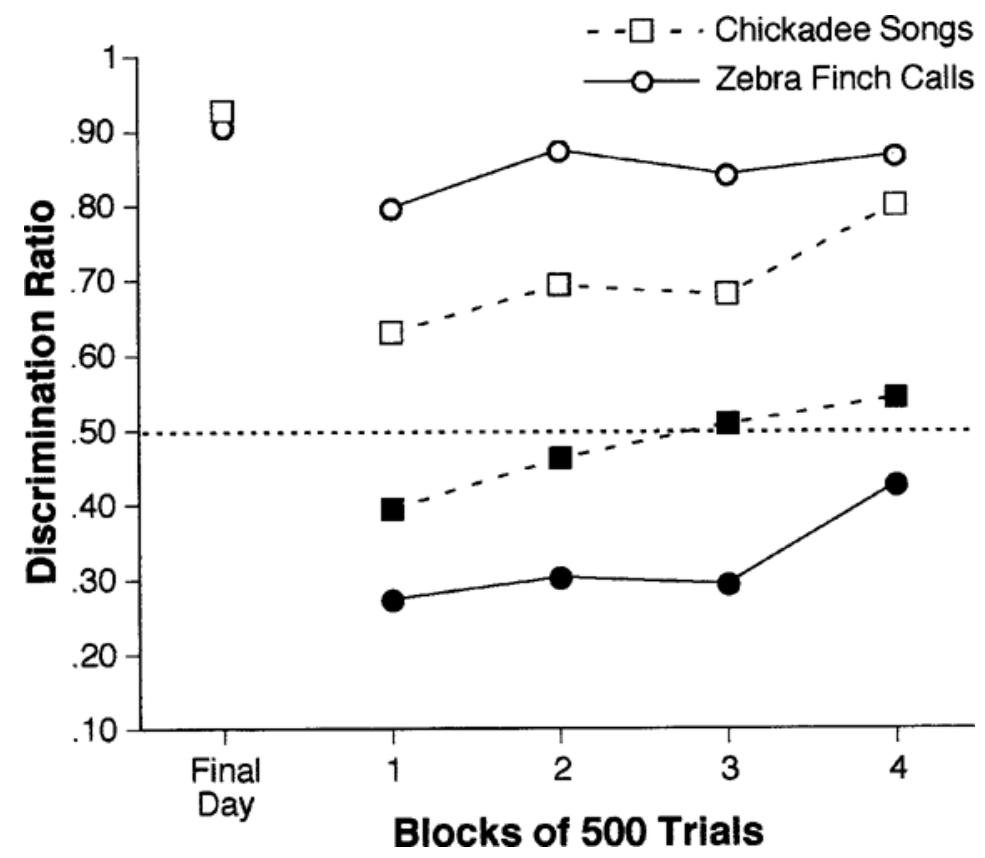

Figure 3. Discrimination ratios for 2,000 trials of transfer to 25-m (degraded) vocalizations for both the consistent (open symbols) and the reversal (closed symbols) groups. Ratios for zebra finch calls are shown as circles, and ratios for chickadee songs are shown as squares. Note that low discrimination ratios for the reversal group are evidence of negative transfer. Discrimination ratios from the final day of the $8 \mathrm{~S}+$ discrimination are shown for reference.

\section{GENERAL DISCUSSION}

Our results show that male black-capped chickadees can discriminate among 16 oscine vocalizations: eight male chickadee songs and eight female zebra finch distance calls. We found that chickadees learned to discriminate among conspecific songs and heterospecific calls at about the same rate and to the same high asymptotic level of discrimination performance. Also, we found that chickadees transferred both discriminations from 5-m vocalizations to 25-m vocalizations. The demonstration that chickadees recognize individual vocalizations even when they are degraded by distance effects is especially compelling because we obtained both positive and negative transfer of recognition from undegraded to degraded vocalizations.

\section{Discrimination of Conspecific and Heterospecific Vocalizations}

We expected that chickadees might have an advantage in discriminating among conspecific vocalizations, relative to discriminating among the vocalizations of another species. Instead, the chickadees discriminated among heterospecific calls about as well as among conspecific songs. Also, the chickadees showed no differences in transferring their discriminations to degraded versions of either conspecific or heterospecific vocalizations. One might expect that birds have an evolutionary advantage in discriminating among conspecific vocalizations, but other results, even better discriminations among heterospecific vocalizations, are logically possible (see Loesche et al., 1991).

We propose several hypotheses about why chickadees discriminate among the zebra finch calls about as well as among conspecific songs. First, songbirds may have a general ability to discriminate among vocalizations independent of the species of the singer. In other words, the perceptual skills chickadees use to discriminate among conspecific songs and calls may be equally effective for discriminating among the vocalizations of other species. So, although it is difficult to envision adaptive benefits for discriminating among the vocalizations of heterospecifics, one set of perceptual skills may serve equally well for discriminating among conspecifics and among heterospecifics. To further test this idea, one could examine the recognition of individual vocalizations over a broad range of species.

Second, it is possible that the perceptual cues available for discriminating among chickadee songs and among zebra finch calls could be about the same. The fee-bee song is highly tonal and similar in acoustic structure among birds (Weisman et al., 1990). It could be that other chickadee vocalizations are easier to use to discriminate among individuals (e.g., "chick-a-dee" calls; Nowicki, 1989). Perhaps, also, the female zebra finch distance call may be a partic- 
ularly easy vocalization for chickadees to use for individual recognition. The distance call is a complex vocalization and, in common with the chick-a-dee call complex, contains many harmonics and frequency and amplitude modulations (Zann, 1984).

Third, synthesizing our stimulus vocalizations (to eliminate reverberation and frequency attenuation) may have rendered the individual songs and calls less distinct. Reducing the amount of acoustic degradation in our stimulus vocalizations was important to the study. We had to compromise between preserving individual cues and eliminating distance cues from our source stimuli. On balance, it appears that we affected a useful compromise: All 16 stimulus vocalizations were discriminable by chickadees. In future research, we propose to test these ideas about the discriminability of chickadee and zebra finch vocalizations simultaneously by (1) checking for a species discriminability advantage in both chickadees and zebra finches, (2) including chick-a-dee calls (rich in individualfeatures) as stimulus vocalizations, and (3) recording vocalizations from within $5 \mathrm{~m}$ of the singer (to eliminate distance cues without using simulations).

Fourth, our version of the go/no-go discrimination methodology might have been insufficient for detecting differences between chickadees' abilities to discriminate among conspecific and among heterospecific vocalizations. However, our go/no-go discrimination methodology has been sensitive enough to (1) detect the discrimination of individual notes within note types (Sturdy, Phillmore, Price, $\&$ Weisman, 1999), (2) to detect differences between withinnote type and between-note type discriminations (Sturdy et al., 2000), and (3) to detect the graded generalization of responding based on distance cues (Phillmore et al., 1998). Also, in experiments using the same stimuli as the present work, Phillmore et al. found that both chickadees and zebra finches discriminated the distance cues faster in chickadee songs than in zebra finch calls. In other words, the go/nogo methodology used here, in other studies of auditory perception in songbirds (e.g., Loesche et al., 1991), and in studies of visual cognition in other species, (e.g., Gottselig, Wasserman, \& Young, 2001) are adequate to detect real differences in the learning and perception of songbirds.

It is possible that other methodologies (e.g., Dooling et al., 1992) might have allowed us to detect a speciesspecific advantage. However, our findings do not suggest that another methodology might have pried apart the data in favor of a conspecific advantage. In Experiment 1, acquisition of discriminations among chickadee songs and among zebra finch calls was virtually identical (see Figure 2). In Experiment 2, the results were opposite to what would be expected for a species-specific advantage; chickadees showed better transfer to heterospecific vocalizations (see Figure 3). There are several possible explanations for why we found no difference between discriminations among conspecific and among heterospecific vocalizations; however, it is unlikely that this result is due to any insensitivity of our methodology.

\section{Positive and Negative Transfer to Degraded Vocalizations}

Our most important findings are that chickadees have the perceptual ability to recognize familiar $S+$ and $S$ - vocalizations despite transformations by distance cues (from 5 to $25 \mathrm{~m}$ ) and that operant discrimination in the laboratory can be used to study this ability. Here, the small, significant drop in performance between 5- and 25-m vocalizations indicates that chickadees recognized the $25-\mathrm{m}$ vocalizations as different but still classified them correctly (as the same vocalizations heard in training).

Identifying individual vocalizations despite their transformation by distance cues is a naturally occurring and biologically relevant example of perceptual constancy. In the wild, the recognition of individual songs and calls is an asset in territorial defense. The task in territorial defense is to determine whether a vocalization originates from a familiar individual or from a stranger and to estimate the distance to the source of the vocalization. Of course, the perceptual constancy of the auditory cues used to perform these tasks must eventually break down over increasing distance. That is, at some point, distance effects must degrade a stimulus to such a degree that a bird can no longer recognize it as a neighbor's vocalization. Laboratory experiments using the procedures developed here with vocalizations degraded in progressively increasing amounts will help determine the limits of individual voice constancy over distance.

Researchers have had only limited success in demonstrating the constancy of individual recognition across vocalizations in the laboratory. Stoddard et al. (1992) and Beecher, Campbell, and Burt (1994) failed to demonstrate transfer across song types in male song sparrows. However, Weary and Krebs (1992) were able to demonstrate the constancy of individual recognition between a limited number of different song types in great tits (Parus major). Our choice of the reversal procedure probably contributed to our successful demonstration of durable constancy across distance. The evidence for negative transfer was particularly striking; birds persisted in responding to distance-degraded versions of previously rewarded vocalizations, even though they were not rewarded during transfer. Perhaps the reversal method will prove useful in studying transfer across song renditions and song types.

\section{Laboratory and Field Studies of Individual Song and Call Recognition}

Our results show transfer of discrimination from 16 vocalizations recorded at $5 \mathrm{~m}$ to novel versions of the same 16 songs and calls rerecorded at $25 \mathrm{~m}$. That is, chickadees recognized the songs and calls despite degradation produced by rerecording at a moderate distance. This is an important type of voice constancy, but different from Weary and Krebs's (1992) demonstration of constancy across song types in great tits. Transfer across song types is not widely replicated (but see Gentner \& Hulse, 1998, for evidence of voice transfer in starlings). Obviously, both types of voice constancy (across transformations by distance and song types) 
are important to songbirds. The ability to recognize individuals by their vocalizations over distance has adaptive significance in making territorial defense viable as a mating strategy. A territory holder that is able to discriminate between neighbors and strangers over various distances can conserve energy by responding aggressively to only those conspecifics that pose a threat.

Field-oriented biologists and laboratory-oriented comparative psychologists sometimes appear to be facing one another across a great divide. For example, a field biologist might see the long training required for chickadees to discriminate among eight vocalizations (our four S + discrimination) as inconsistent with results from field playback studies of neighbor recognition. In Experiment 1, we examined how long chickadees took to learn to discriminate among vocalizations, whereas in field playback studies, recognition well after learning has occurred is examined. Therefore, the training required to demonstrate acquisition of discrimination among vocalizations is not inconsistent with the few trials required to demonstrate recognition of already-learned neighbors; these two types of studies are testing two different processes. In fact, Experiment 2 is quite comparable to field studies of recognition, in which we demonstrate recognition in only a few trials (see Figure 3).

There is the matter of whether songbirds require fewer trials to learn about their territorial neighbors than our subjects required to discriminate among several individual vocalizations. It seems reasonable to suppose that at least some exposure would be necessary for a new territory holder to accurately discriminate among its neighbors' songs. In the field, individual chickadees may hear over 600 songs per day from different neighbors (Otter \& Ratcliffe, 1993). In Experiment 1, chickadees were about $75 \%$ accurate in discriminating among eight individual vocalizations in 4,500 trials, which translates to fewer than 600 trials per vocalization. Therefore, the amount of vocalization our subjects experienced was comparable to the amount that chickadees hear during a single day while learning to recognize territorial neighbors. However, more field research is required to determine exactly how much experience songbirds in general (and chickadees in particular) require to learn the vocalizations of their neighbors.

Another issue on which field biologists and comparative psychologists seem to disagree is the relevance of studies of food-rewarded operant discriminations to understanding the behavior of songbirds in nature. Field biologists clearly have a point; the context in which discriminations are performed is relevant to whether songbirds will attend to any particular auditory stimulus. Consider two examples. Most often in the field, songbirds attend to the songs of conspecifics and ignore those of heterospecifics (McGregor, 1991). In the field, songbirds sometimes respond with equal vigor to a conspecific song presented at different distances within their territories (e.g., Fotheringham $\&$ Ratcliffe, 1995). A simplistic interpretation of these findings might be that in the field, male songbirds can perceive conspecifics, but not heterospecifics, and also fail to perceive cues for distance within their territories. Operant studies (e.g., the present research; Phillmore et al., 1998) can help researchers to separate contextual control of attention from perceptual competence. Furthermore, there is evidence to suggest that the results of operant perceptual experiments are relevant to understanding songbirds' use and perception of vocalizations in the field. For example, a healthy interaction between field and laboratory researchers has helped explicate the importance of absolute pitch perception in songbirds' recognition of the songs of conspecifics (see Lohr \& Dooling, 1998; Nelson, 1989; Weisman et al., 1998).

Field playback studies of individual recognition have the advantage of transmitting their test stimuli over true natural space, whereas laboratory studies can only present recordings of test stimuli previously degraded by natural space at a close physical distance. However, in the laboratory, we can present vocalizations with precise degrees of degradation, we can use reversal techniques to test for the occurrence and strength of transfer to novel stimuli, and we can test responses to heterospecific vocalizations. In the course of reporting the results of this and similar research (see Phillmore et al., 1998), it has occurred to us to combine field and laboratory techniques in further experiments on individual recognition over distance. Operant training in an outdoor aviary may allow us to manipulate perceptual and natural space simultaneously.

\section{REFERENCES}

Ast ley, S. L., \& Wasserman, E. A. (1992). Categorical discrimination and generalization in pigeons: All negative stimuli are not created equal. Journal of Experimental Psychology: Animal Behavior Processes, 18, 193-207.

Beecher, M. D., Campbell, S. E., \& Burt, J. M. (1994). Song perception in the song sparrow: Birds classify by song type but not by singer. Animal Behaviour, 47, 1343-1351.

BRooks, R. J., \& FALLS, J. B. (1975). Individual recognition by song in white-throated sparrows: I. Discrimination of songs of neighbors and strangers. Canadian Journal of Zoology, 53, 879-888.

Conover, W. J., \& Iman, R. L. (1981). Rank transformations as a bridge between parametric and nonparametric statistics. American Statistician, 35, 124-129.

Dabelsteen, T., Larsen, O. N., \& Pedersen, S. B. (1993). Habitatinduced degradation of sound signals: Quantifying the effects of communication sounds and bird location on blur ratio, excess attenuation, and signal-to-noise ratio in blackbirds song. Journal of the Acoustical Society of America, 93, 2206-2220.

Dawson, A., King, V. M., Bentley, G. E., \& Ball, G. F. (2001). Photoperiodic control of seasonality in birds. Journal of Biological Rhythms, 16, 365-380.

Dooling, R. J., Brown, S. D., Klump, G. M., \& OKanoya, K. (1992). Auditory perception of conspecific and heterospecific vocalizations in birds: Evidence for special processes. Journal of Comparative Psychology, 106, 20-28.

FAlls, J. B., \& BrooKs, R. J. (1975). Individual recognition by song in white-throated sparrows: II. Effects of location. Canadian Journal of Zoology, 53, 1412-1420.

Fotheringham, J. R, \& Ratcliffe, L. (1995). Song degradation and estimation of acoustic distance in black-capped chickadees (Parus atricapillus). Canadian Journal of Zoology, 73, 858-868.

Gentner, T., \& Hulse, S. (1998). Perceptual mechanisms for individ- 
ual vocal recognition in European starlings, Sturnus vulgaris. Animal Behaviour, 56, 579-594.

GoDARD, R., \& WiLEy, R. H. (1995). Individual recognition of song repertoires in two wood warblers. Behavioral Ecology \& Sociobiology, 37, 119-123.

Gottselig, J. M., Wasserman, E. A., \& Young, M. E. (2001). Attentional trade-offs in pigeons learning to discriminate newly relevant visual stimulus dimensions. Learning \& Motivation, 32, 240-253.

Loesche, P., Stoddard, P. K., Higgins, B. J., \& Beecher, M. D. (1991). Signature versus perceptual adaptations for individual vocal recognition in swallows. Behaviour, 118, 15-25.

Lohr, B., \& Dooling, R. J. (1998). Detection of changes in timbre and harmonicity in complex sounds by zebra finches (Taeniopygia guttata) and budgerigars (Melopsittacus undulatus). Journal of Comparative Psychology, 112, 36-47.

McGregor,P. K. (1991). The singer and the song: On the receiving end of bird song. Biological Review, 66, 57-81.

NAGUIB, M. (1995). Auditory distance assessment of singing conspecifics in Carolina wrens: The role of reverberation and frequency attenuation. Animal Behaviour, 50, 1297-1307.

NAGUib, M. (1997). Use of song amplitude for ranging in Carolina wrens, Thryothorus ludovicianus. Ethology, 103, 723-731.

Nelson, B. S., \& StOdDARD, P. K. (1998) Accuracy of auditory distance and azimuth perception by a passerine bird in natural habitat. Animal Behaviour, 56, 467-477.

Nelson, D. A. (1989). Song frequency as a cue for recognition of species and individuals in the field sparrow (Spizella pusilla). Journal of Comparative Psychology, 103, 171-176.

Nuegovan, M., Hilhorst, B., Ferguson, S., \& Weisman, R. (1994). A motor driven feeder for operant training in song birds. Behavior Research Methods, Instruments, \& Computers, 26, 26-27.

Nuegovan, M., \& Weisman, R. (1997). Pitch discrimination in fieldand isolation-reared black-capped chickadees (Parus atricapillus). Journal of Comparative Psychology, 111, 294-301.

NowICKI, S. (1989). Vocal plasticity in captive black-capped chickadees: The acoustic basis and rate of call convergence. Animal Behaviour, 37, 64-73.

OtTER, K., \& RATCLIFFe, L. (1993). Changes in singing behavior of male black-capped chickadees (Parus atricapillus) following mate removal. Behavioral Ecology \& Sociobiology, 133, 409-414.

Phillmore, L., Sturdy, C., Ramsay, S., \& Weisman, R. (1998). Discrimination of auditory distance cues by black-capped chickadees (Poecile atricapillus) and zebra finches (Taeniopygia guttata). Journal of Comparative Psychology, 112, 282-291.
Searcy, W. A., McArthur, P. D., Peters, S. S, \& Marler, P. (1981). Response of male song and swamp sparrows to neighbor, stranger, and self songs. Behaviour, 77, 152-163.

Shy, E., \& MorTon, E. S. (1986). The role of distance, familiarity, and time of day in Carolina wrens responses to conspecific songs. Behavioural Ecology \& Sociobiology, 19, 393-400.

Slater, P. J. B., \& Catchpole, C. K. (1990). Responses of the two chaffinch species on tenerife (Frengilla teyda and F. coelebs tintillon) to playback of the song of their own and the other species. Behaviour, 115, 143-152.

Sokal, R. R. \& Rohlf, F. J. (1980). Biometry. New York: Freeman.

Stoddard, P. K., Beecher, M. D., Loesche, P., \& Campbell, S. E (1992). Memory does not constrain individual recognition in a bird with song repertoires. Behaviour, 122, 274-287.

Sturdy, C. B., Phillmore, L. S., Price, J. L., \& Weisman, R. G. (1999). Song-note discriminations in zebra finches (Taeniopygia guttata): Categories and pseudocategories. Journal of Comparative Psychology, 113, 204-212.

Sturdy, C. B., Phillmore, L. S., \& Weisman, R. G. (2000). Call-note discriminations in black-capped chickadees (Poecile atricapillus). Journal of Comparative Psychology, 114, 357-364.

WeARY, D. M., \& KREBS, J. R. (1992). Great tits classify songs by individual voice characteristics. Animal Behaviour, 43, 283-287.

Weary, D. M., Lemon, R. E., \& Perreault, S. (1992). Song repertoires do not hinder neighbor-stranger discrimination. Behavioural Ecology \& Sociobiology, 31, 441-447.

Weisman, R, NJegovan, M., \& Ito, S. (1994). Frequency-ratio discrimination by zebra finches (Taeniopygia guttata) and humans (Homo sapiens). Journal of Comparative Psychology, 108, 363-372.

Weisman, R., Nuegovan, M., Sturdy, C., Phillmore, L., Coyle, J., \& Mewhort, D. (1998). Frequency range discriminations: Special and general abilities in zebra finches (Taeniopygia guttata) and humans (Homo sapiens). Journal of Comparative Psychology, 112, 244-258.

Weisman, R, Ratcliffe, L., Johnsrude, I., \& Hurley, T. A. (1990). Absolute and relative pitch production in the song of the black-capped chickadee. Condor, 92, 118-124.

WiLEY, R. H. (2000). A new sense of the complexities of bird song. Auk, 117, 861-868.

ZANN, R. (1984). Structural variation in the zebra finch distance call. Zeitschrift für Tierpsychologie, 66, 328-345.

(Manuscript received April 30, 2001; revision accepted for publication October 4, 2001.) 